\title{
Mechanisms of Cell Polarity-Controlled Epithelial Homeostasis and Immunity in the Intestine
}

\author{
Leon J. Klunder, ${ }^{1}$ Klaas Nico Faber, ${ }^{2}$ Gerard Dijkstra, ${ }^{2}$ and Sven C.D. van IJzendoorn ${ }^{1}$ \\ ${ }^{1}$ Department of Cell Biology, University Medical Center Groningen, University of Groningen, 9713 GZ \\ Groningen, the Netherlands \\ ${ }^{2}$ Department of Gastroenterology and Hepatology, University Medical Center Groningen, \\ University of Groningen, 9713 GZ Groningen, the Netherlands \\ Correspondence: s.c.d.van.ijzendoorn@umcg.nl
}

\begin{abstract}
Intestinal epithelial cell polarity is instrumental to maintain epithelial homeostasis and balance communications between the gut lumen and bodily tissue, thereby controlling the defense against gastrointestinal pathogens and maintenance of immune tolerance to commensal bacteria. In this review, we highlight recent advances with regard to the molecular mechanisms of cell polarity-controlled epithelial homeostasis and immunity in the human intestine.
\end{abstract}

Intes ntestinal epithelial cells (IECs) are short-lived cells forming a barrier and facing the lumen of the gut. As such, intestinal epithelial cells are responsible for the metabolism and uptake of diet-derived nutrients and for their transfer to the tissue side where they can enter the blood circulation. IECs are also the first line of defense against ingested potential pathogens. The lumen of the intestinal tract, however, is also colonized by trillions of commensal bacteria that play important roles in normal physiology. IECs are thus confronted with the challenging task of maintaining good relationships with these bacteria yet prevent these bacteria from entering the body tissue. At the tissue side, IECs must maintain good relationships with the immune system, which actively monitors and probes the microbiota via intraepithelial immune cells. IECs, thus, ensure carefully balanced communications between the gut lumen and bodily tissue, thereby controlling the defense against gastrointestinal pathogens while maintaining immune tolerance to commensal bacteria.

\section{A BRIEF INTRODUCTION TO EPITHELIAL CELL POLARITY IN THE INTESTINE}

IECs (also called enterocytes) comprise the vast majority of all cell types in the intestinal epithelium (including paneth cells, enteroendocrine cells, and goblet cells). IECs are arranged as a monolayer of columnar-shaped, polarized epithelial cells (Fig. 1A). Cells predominantly communicate with their environment via proteins

Editor: Keith E. Mostov

Additional Perspectives on Cell Polarity available at www.cshperspectives.org

Copyright (C) 2017 Cold Spring Harbor Laboratory Press; all rights reserved; doi: 10.1101/cshperspect.a027888

Cite this article as Cold Spring Harb Perspect Biol 2016;9:a027888 
L.J. Klunder et al.

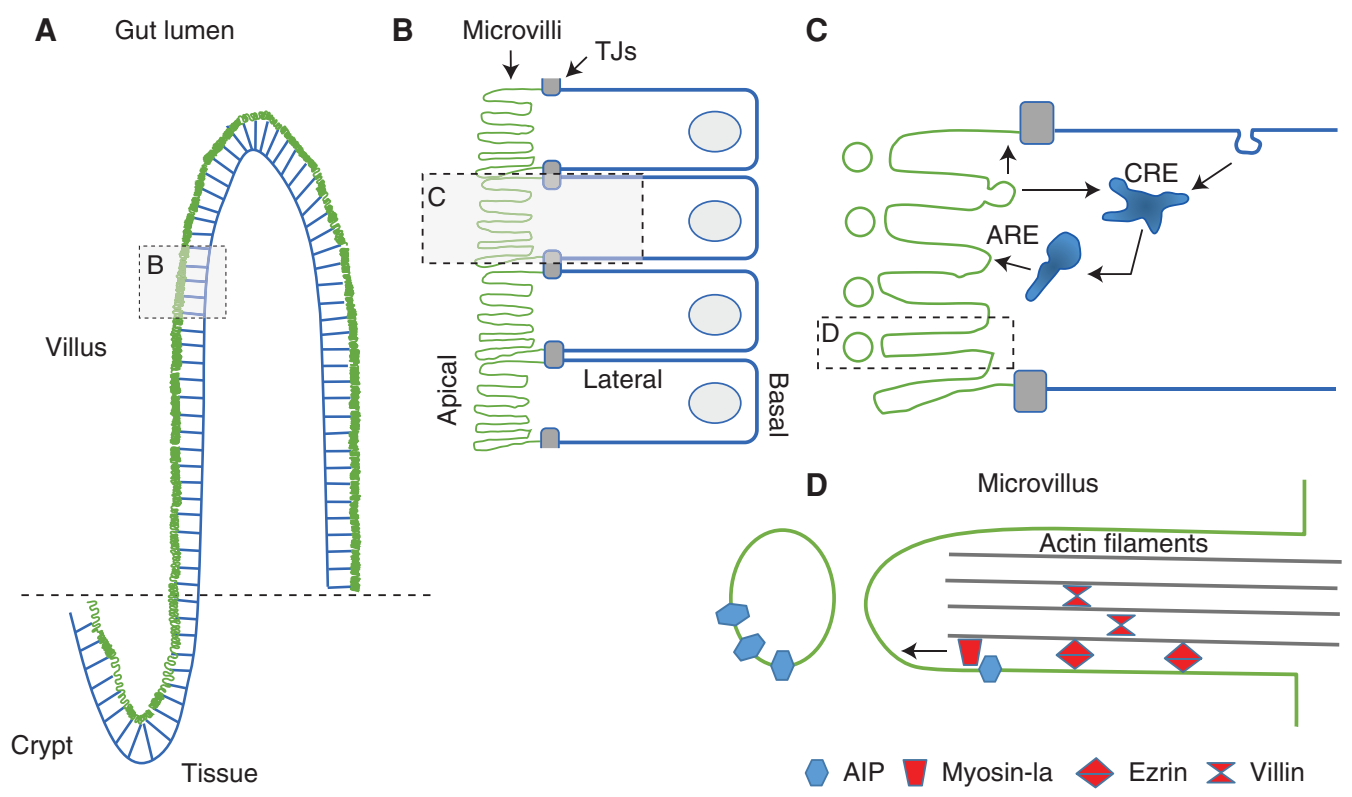

Figure 1. Intestinal epithelial cell polarity. (A) Crypt-villus organization of the intestinal epithelial cell monolayer. $(B)$ Detail of the boxed area in panel $A$, showing the apical, basal, and lateral surface polarity of the individual enterocyte. $(C)$ Detail of the boxed area in panel $B$, showing the common/apical recycling endosome (CRE) and the apical recycling endosome (ARE) in the individual enterocyte. $(D)$ Detail of the boxed area in panel $C$, showing a single microvillus and a microvillus-derived vesicle. TJ, Tight junction; AIP, alkaline intestinal phosphatase; ARE, apical recycling endosome; CRE, common recycling endosome.

(receptors, transporters, channels) at their surface. The surface (or plasma membrane) of the IEC is divided into one apical and one basolateral domain, which face the lumen of the gut and the intestinal tissue, respectively. The basolateral cell-surface domain can be further divided in a basal and a lateral domain that face the basement membrane and neighboring cells, respectively (Fig. 1B). The lateral surface houses intercellular adhesions, including E-cadherinbased adherens junctions (AJs) and claudinbased tight junctions (TJs), which ensure monolayer strength and impermeability, respectively (Giepmans and van Ijzendoorn 2009). The basal surface is home to integrin-based cell-matrix adhesions, via which the cells are attached to the basement membrane. Planar polarity mechanisms ensure that all IECs orientate their apical and basal surface domains in the same direction.

The apical and basal cell-surface domains are distinguished with regard to structural or- ganization and macromolecular composition. Only the apical plasma membrane displays densely packed actin filament-based projections called microvilli (Fig. 1B) (Crawley et al. 2014). In addition to their structural differences, the apical and basal plasma membrane domains are differently equipped with proteins to control the metabolism, absorption, and/or secretion of nutrients between the gut lumen, cell interior, and body tissue. The polarized distribution of cell-surface receptors and transporter proteins allows for the vectorial transport of circulating nutrients and immunoglobulins across the intestinal epithelial monolayer. Not surprisingly, the mislocalization of apical brush-border proteins leads to malnutrition, diarrheal disorders, and, if untreated, to death (Overeem et al. 2016). The mislocalization of integrins at the opposing basal surface domain correlated with loss of epithelial architecture and cancer development (Krishnan et al. 2013). Further, the polarized basal expression of cytokine receptors mediate 
the cytokine-mediated communication with immune cells in the lamina propria, whereas the polarized apical expression of several pattern-recognition receptors controls the induction of innate immunity responses. Defects in the mechanisms that control apical microvilli development or the polarized distribution of cytokine receptors or pattern-recognition receptors result in the perturbation of intestinal epithelial-microbial interactions and gut immune homeostasis in mice, and often contribute to the pathogenesis of inflammatory bowel diseases in humans (Takahashi et al. 2011; Shifrin and Tyska 2012; Shifrin et al. 2012; Yu et al. 2014), as will be further discussed below.

Intracellular sorting and trafficking secures the polarized distribution of integral membrane proteins at the apical and basal plasma cellsurface domains (van der Wouden et al. 2003; Weisz and Rodriguez-Boulan 2009). The Golgi apparatus is well known for its role in the polarized sorting and trafficking of proteins. In addition, the endosomal system and its associated small GTPases Rab8, Rab11, Rab25, and their effectors, and the epithelium-specific polarized sorting factor adaptor protein (AP)-1B have, in the last decade, emerged as important regulators of polarized sorting and trafficking of proteins (Sato et al. 2007; Golachowska et al. 2010; Shifrin and Tyska 2012; Shifrin et al. 2012; Knowles et al. 2014). Intracellular sorting and trafficking also controls the constitutive or regulated polarized secretion of signaling molecules such as growth factors, cytokines, and antimicrobial products. Recycling endosomes have been implicated in the polarized secretion of cytokines in immune cells (Stow and Murray 2013) and neuronal cells (Moidunny et al. 2012), but the mechanisms of polarized cytokine secretion in IEC (Rossi et al. 2013) is not well understood.

TJs situated at the border between the apical and basal cell-surface domains establish tight cell-cell adhesion, and restrict the lateral diffusion of apical and basal cell-surface proteins, thereby securing cell-surface polarity (Fig. 1B). TJs, by virtue of the pore-forming claudins, also control the paracellular transport of electrolytes and water (Giepmans and van Ijzendoorn 2009;
Marchiando et al. 2010), and mediate the compartmentalization of secreted molecules in either gut lumen or lamina propria (Marques and Boneca 2011; Wells et al. 2011). TJs and, consequently, the intestinal barrier are often impaired in inflammatory bowel disorders (IBDs, comprising Crohn's disease and ulcerative colitis), allowing the translocation of pathogens or pathogen-derived molecules (Marchiando et al. 2010). TJs also recruit transcription factors and prevent their translocation to the nucleus, and thereby contribute to cell proliferation regulation (Matter et al. 2005). The aberrant expression or distribution of several TJ-associated proteins has been implicated in colon cancer development and progression (Wang et al. 2011; Singh and Dhawan 2015), underscoring the importance of TJs in intestinal epithelial homeostasis.

The polarized intracellular trafficking machinery and TJs are central players in the epithelial polarity program (Rodriguez-Boulan and Macara 2014). Evolutionary conserved polarity protein complexes are the core components of this epithelial polarity program. Three polarity complexes are typically distinguished: a complex consisting of Crb3a, Pals1, and PATJ, a complex consisting of Par3, Par6, atypical (a) protein kinase $\mathrm{C}$ (PKC), and the small GTPase Cdc42, and a complex consisting of Lgl, Dlg, and Scribble (Rodriguez-Boulan and Macara 2014). Impaired expression or function of many core cell polarity-determining proteins has been correlated with impaired intestinal epithelial homeostasis (Sakamori et al. 2012; Melendez et al. 2013; Whiteman et al. 2014; Charrier et al. 2015) and inflammatory bowel disorders (Weersma et al. 2009; Ivanov et al. 2010; Mashukova et al. 2011; Wald et al. 2011; Schumann et al. 2012; Xu et al. 2014).

Taken together, intestinal epithelial cellsurface polarity and TJs are instrumental to balance communications between the gut lumen and bodily tissue and control the defense against gastrointestinal pathogens and maintenance of immune tolerance to commensal bacteria (Marques and Boneca 2011; Wells et al. 2011; Rossi et al. 2013). Below, we highlight recent advances with regard to the molecular mechanisms of cell 
L.J. Klunder et al.

polarity-controlled epithelial homeostasis and immunity in the intestine.

\section{APICAL BRUSH-BORDER DYNAMICS CONTRIBUTE TO EPITHELIAL HOMEOSTASIS AND INNATE IMMUNITY IN THE GUT}

Apical microvilli greatly enlarge the absorptive cell-surface area while minimally influencing cellular volume. In agreement, apical microvillus atrophy has been correlated with suboptimal absorption of dietary nutrients. Interestingly, recent studies have shown novel roles for apical plasma membrane microvilli and their protein components in intestinal epithelial cells beyond absorptive surface expansion.

Villin is an actin-modifying protein in intestinal epithelial cells exclusively located in apical plasma membrane microvilli and the underlying subapical terminal web (Fig. 1D) (Khurana and George 2008). Targeted disruption of the villin-encoding gene in mice did not impair the organization of apical microvilli, suggesting that villin plays a minor or redundant role in microvilli development (Pinson et al. 1998). Villin was required to sever filamentous actin to depolarize microvilli and, in this way, allow IEC migration and remodeling on mucosal injury (Ubelmann et al. 2013). Villin is also subject to proteolysis following gut infection and during the recovery phase of gut infection (Solaymani-Mohammadi and Singer 2013). Villin expression in IEC is reduced in IBD characterized by recurring inflammation and associated lesions (Kersting et al. 2004). These results highlight the importance of the apical polarity of IEC and, specifically, apical plasma membrane microvilli and their dynamics, in the process of gut wound healing and, hence, intestinal epithelial homeostasis and immunopathology.

While the regulated breakdown of apical microvilli appears to be necessary for gut wound healing, apical microvilli are also important for maintaining intestinal epithelial homeostasis. This is well exemplified by the deletion of ezrin, the only member of the ezrin-radixin-moesin (ERM) family of membrane-actin cross-linking proteins present in intestinal epithelial cells. Deletion of ezrin led to apical microvillus atrophy throughout the intestinal epithelium, and resulted in villus morphogenesis defects (i.e., villus fusions) and neonatal death in mice (Saotome et al. 2004; Casaletto et al. 2011). Similar effects were observed in Crumbs3-deficient mice (Whiteman et al. 2014; Charrier et al. 2015), presumably because of the functional interaction between Crumbs3 and ezrin (Whiteman et al. 2014). Moreover, villus fusions were also reported in humans with microvillus inclusion disease and carrying $M Y O 5 B$ mutations (Dhekne et al. 2014). Loss of the myosin $\mathrm{Vb}$ protein in these individuals was shown to inhibit the activation of ezrin at the apical surface and lead to microvillus atrophy in their intestinal epithelial cells (Dhekne et al. 2014). The loss of ezrin-mediated microvillus atrophy in the adult mouse intestine caused defects in cell geometry, cell extrusion, cell-cell adhesion remodeling, and mitotic spindle orientation (Casaletto et al. 2011), which are essential for epithelial homeostasis and villus morphogenesis. By contrast, an increased expression of ezrin has been correlated with elongated apical microvilli in the small intestine of vitamin D receptor knockout mice (Kühne et al. 2015). Ezrin is proteolytically cleaved in mice with intestinal inflammation in a $\mathrm{CD}^{+}$T-cell-dependent manner (Solaymani-Mohammadi and Singer 2013), but the physiological or pathophysiological relevance of this phenomenon is not clear.

The intestinal brush border, in agreement with its role in the regulation of epithelial tissue morphogenesis and architecture (see above), protects against carcinogenesis. Thus, the loss or inactivation of myosin-Ia, another abundant component of microvilli (Fig. 1D) and necessary for microvilli development (Tyska et al. 2005), leads to the loss of IEC polarity, carcinogenic behavior of IEC, and tumor development in mice (Mazzolini et al. 2012). These results point to a functional link between apical plasma membrane architecture and epithelial homeostasis.

Apical microvilli are highly dynamic structures, governed by interactions between the apical plasma membrane and the underlying actin 
cytoskeleton. The motor activity of myosin-Ia and myosin-VI controls the microvillus tip- and base-directed movement, respectively, of the plasma membrane along the actin filaments that make up the microvillus core (McConnell and Tyska 2007). As such, these myosins regulates the intramicrovillus (that is, microvillus tip versus microvillus base) distribution of brush-border enzymes (Tyska and Mooseker 2004; Hegan et al. 2012; Chen et al. 2014). Interestingly, the tips of the apical microvilli give rise to vesicles that are shed into the gut lumen (McConnell et al. 2009). These microvillus-derived vesicles are enriched in the IAP (Fig. 1D). This enzyme allows the vesicles to dephosphorylate and, thereby, detoxify bacterial lipopolysaccharide and prevent Toll-like receptor4 (TLR4) responses on host cells (Poelstra et al. 1997; Tuin et al. 2009). Furthermore, the exposure of IEC to Escherichia coli induced the expression of IAP and the production of microvilli-derived vesicles, which, in turn, inhibited E. coli proliferation and the attachment of these bacteria to the host cells in vitro, albeit in an IAP-independent manner (Shifrin et al. 2012). The activity of myosin-Ia appears to be crucial for the correct assembly of these microvilli-derived vesicles, as microvilli-derived vesicles in mice and cell lines lacking myosin-Ia were not enriched in intestinal alkaline phosphatase but, rather, displayed a protein composition that was similar to the overall enterocyte brush border (Shifrin et al. 2012). Together, apical brushborder microvilli release membrane vesicles into the intestinal lumen, which are laden with a host defense machinery, representing a new role for apical plasma membrane microvilli in intestinal innate immunity (Shifrin and Tyska 2012). Whether loss of villin, ezrin, or myosin- $\mathrm{Vb}$ and resultant microvillus atrophy affects the release of microvilli-derived vesicles and therewith associated functions, and whether microvilli-derived membrane vesicles contribute to intestinal epithelial wound healing, homeostasis, and/or tumor suppression, is not known.

In conclusion, these studies have shown novel roles for apical plasma membrane microvilli and their protein components in wound healing, epithelial homeostasis and tumor suppression, and innate immunity in the gut.

Polarized Endosomal Sorting and Trafficking Mechanisms Control Epithelial Homeostasis, Tumor Suppression, and Innate Immunity in the Gut

The endosomal system has emerged as a crucial regulator of polarized sorting and trafficking of cell-surface proteins in epithelial cells (Golachowska et al. 2010). In addition, the spatial distribution of endosomal system provides polarized signaling platforms (Bryant et al. 2010; Dhekne et al. 2014; Kravtsov et al. 2014) that control the activation of ezrin at the apical surface of intestinal epithelial cells and, thereby, the development of the apical brush-border membrane (Dhekne et al. 2014). Within the complex endosomal system (Perret et al. 2005; Bay et al. 2015), two endosomal subcompartments have been identified that appear particularly important for the correct sorting and trafficking of apical and basal proteins: the apical recycling endosome (ARE) and the common recycling endosome (CRE) (Fig. 1C). The ARE is characterized by the presence of Rab8, Rab11a, Rab25, and their common effector protein, myosin- $\mathrm{Vb}$. The ARE is predominantly accessible for resident apical proteins and functions in the dispatch of newly synthesized and apically recycling and/or transcytosing proteins to the apical brush-border membrane. The CRE is characterized by its accessibility to proteins internalized from either apical or basal surface domain (Hughson and Hopkins 1990) and contains the polarized sorting factor adaptor protein $\mathrm{AP}-1 \mathrm{~B}$, which is believed to control sorting of proteins to the basal cell surface. Noteworthy, most of the knowledge about the organization of the endosomal system in polarized cells is derived from Madin-Darby canine kidney (MDCK) epithelial cells (Perret et al. 2005; Bay et al. 2015). Whether this organization of the endosomal system is similar in IEC has not been carefully addressed. Nevertheless, components of the ARE and/or CRE play a role in the regulation of epithelial homeostasis, tumor 
L.J. Klunder et al.

suppression, and innate immunity in the gut, as outlined below.

\section{The Apical Recycling Endosome}

Intestine-specific Rab11a knockout mice show intracellular accumulation and mislocalization of resident apical plasma membrane proteins to the basal surface domain, microvillus atrophy, and microvillus inclusion bodies (Sobajima et al. 2014a; Knowles et al. 2015). Some apical proteins, such as dipeptidyl peptidase-IV, and IAP are downregulated in the intestinal epithelial cells of Rab11a knockout mice, whereas the polarized distribution of basal proteins appeared unaffected. Rab11a knockout mice die in the postnatal period as a consequence of starvation. IEC of intestine-specific Rab8 or Myo5b-knockout mice, and individuals with microvillus inclusion disease that carry $M Y O 5 B$ mutations show very similar intracellular accumulation of resident apical plasma membrane proteins, microvillus atrophy, and microvillus inclusion bodies, yet died of diarrhea (Cutz et al. 1989; Ameen and Salas 2000; Sato et al. 2007; Cartón-García et al. 2015; Schneeberger et al. 2015; Weis et al. 2016). The apical transport abnormalities in IEC in Rab8-deficient mice may be the result of effects of Rab8a depletion on the secretion of Wnt ligands, which play an important role in intestinal epithelial morphogenesis (Das et al. 2015). The aberrant expression or function of either Rab11a, Rab8, or myosin $\mathrm{Vb}$ in mice or humans affected each other's expression or subcellular distribution in IEC (Sato et al. 2007; Szperl et al. 2011; Golachowska et al. 2012; Sakamori et al. 2012; Dhekne et al. 2014; Sobajima et al. 2014b). Together, these results support the in vitro evidence that Rab11a, Rab8, and myosin Vb operate in the same pathway that controls the trafficking of apical brush-border proteins and development of apical microvilli in (intestinal) epithelial cells (Bryant et al. 2010; Dhekne et al. 2014; Knowles et al. 2014).

The $R A B 11 A$ gene is located adjacent to a Crohn's disease risk locus (Yu et al. 2014). Intestine-specific Rab11a knockout mice spontaneously develop colitis, and show excessive intes- tinal epithelial proliferation. IEC of Rab11a knockout mice show up-regulation of interleukins -6 and $-1 \mathrm{~B}$ and monocyte chemoattractant protein-1, and show a redistribution of Toll-like receptor-9 (TLR9) from its normal brush-border location to late endosome and/or lysosomes. Stimulation of TLR9 at the apical surface domain of IEC was shown to counteract the activation of nuclear factor $\kappa \mathrm{B}(\mathrm{NF}-\kappa \mathrm{B})$ that curtailed inflammatory responses induced by basal stimulation by other TLRs or tumor necrosis factor receptor $\alpha$ (TNF- $\alpha$ ) (Lee et al. 2006; Ghadimi et al. 2010). Tlr9 knockout mice are highly susceptible to experimental colitis (Lee et al. 2006). In line with this, intestinal epithelial cells of Rab11a knockout mice show upregulated signaling activity through NF- $\kappa \mathrm{B}$ and mitogen-activated protein kinase, which is involved in inflammatory and stress responses (Pasparakis 2009). Moreover, germ-free Rab11a knockout mice failed to tolerate intraluminal stimulation by microbial agonists and induced interleukin- 6 when compared to wild-type mice undergoing the same treatment ( $\mathrm{Yu}$ et al. 2014). Thus, the apical recycling endosome, by virtue of Rab11a, controls subcellular TLR9 compartmentalization and, consequently, is crucial for the regulation of immune tolerance and inflammation.

At least in cultured epithelial MDCK cells, Rab1 1a and Rab8 at ARE coordinate the activation of the small $\rho$ family GTPase Cdc42 (Bryant et al. 2010). In Cdc42-deficient mice, the intestinal epithelium showed gross hyperplasia, crypt enlargement, microvillus inclusions, and brush-border formation at the lateral surface domains, and abnormal epithelial permeability, suggesting a coordinating role for Cdc42 in the polarity, migration, and differentiation of intestinal epithelial cells (Melendez et al. 2013). In other intestine-specific Cdc42-deficient mice, generated independently, impaired Rab8 activation, intestinal stem-cell division, survival, and differentiation of IEC was observed (Sakamori et al. 2012). Also, in human colorectal carcinoma cells, loss of Cdc42 caused mitotic spindle orientation defects and deranged intestinal epithelial morphogenesis (Jaffe et al. 2008). Furthermore, single intestinal LS174:W4 cells show multiple brush-border domains and dis- 
persed apical recycling endosome localization (Bruurs et al. 2015). Notably, in contrast to the loss of Rab11a (Yu et al. 2014), the loss of Cdc42, Rab8, or myosin $\mathrm{Vb}$ did not elicit intestinal inflammation in mice (Melendez et al. 2013). This suggests that the latter three proteins play a minimal or redundant role in the regulation of intestinal immunity, and it will be of interest to investigate the distribution of TLR9 in the IEC of Cdc42-, Rab8-, and Myo5b-deficient mice.

In addition to Rab1la and Rab8, Rab25 is an epithelial-specific component of the ARE (Casanova et al. 1999). Depletion of Rab25 in human intestinal Caco- 2 cells resulted in disorganized apical microvilli, loss of apical villin, and the intracellular retention of the brush-border protein sucrase-isomaltase, without affecting the expression of Rab1 1a or Rab8 (Krishnan et al. 2013). Unlike Rab11a and Rab8, Rab25 has been linked to tumor aggressiveness and metastasis in several tissues (Mitra et al. 2012). Loss of Rab25 was shown to promote the development of intestinal neoplasia and was found to be associated with human colorectal adenocarcinoma's (Nam et al. 2010). As part of the underlying mechanism, loss of Rab25 from intestinal colon carcinoma Caco-2 cells was shown to lead to upregulated claudin-1 expression (previously associated with perturbed intestinal epithelial homeostasis and colon cancer development [Pope et al. 2014]) increased transepithelial resistance and increased invasive behavior (Nam et al. 2010). Loss of Rab25 likely contributed to invasiveness of (colon) cancer cells by regulating basal integrin expression and/or trafficking (Caswell et al. 2007; Krishnan et al. 2013) via the rab-coupling protein (Caswell et al. 2008) and consequent reorganization of the cortical actin cytoskeleton (Jacquemet et al. 2013; Paul et al. 2015). Loss of Rab25 did not appear to affect E-cadherinbased AJs (Krishnan et al. 2013). Together, these findings suggest that Rab25 is an important regulator of intestinal epithelial homeostasis and a tumor suppressor in colon carcinogenesis (Goldenring and Nam 2011). The occurrence of spontaneous colitis, defects in the polarized distribution of TLRs, or alterations in other as- pects of intestinal immunity have not been reported in Rab25-deficient mice. Notably, Rab25 and myosin- $\mathrm{Vb}$ were shown to control the transcytosis of the neonatal major histocompatibility complex class I-related IgG receptor FcRN, when ectopically expressed in MDCK cells, between the apical brush border and the basal surface (Tzaban et al. 2009). In an in vivo setting in the intestine, the loss of Rab25 could then be predicted to impair IgG-mediated humoral immunity of the fetus or newborn, but this has not been shown.

\section{The Common Recycling Endosome}

The best-characterized regulator of polarized protein sorting at the CRE is AP-1B. AP- $1 \mathrm{~B}$ is downregulated in the colonic epithelium of individuals with Crohn's disease (Takahashi et al. 2011). Further, a reduced ratio of tumor to nontumor tissue expression of AP-1B was correlated with nuclear translocation of $\beta$-catenin in human colorectal tumor tissue, indicative for a hyperproliferative state (Mimura et al. 2012).

Deletion of the Ap1m2 gene, which encodes one of the four AP-1B subunits, resulted in the mislocalization of several basolateral proteins in mice. For example, the low-density lipoprotein receptor accumulated in cytoplasmic vesicular structures. $A p-1 B$ deficiency led to mistargeting of a subset of basolateral cytokine receptors to the apical plasma membrane (Takahashi et al. 2011). Also E-cadherin was mislocalized to cytoplasmic structures, the E-cadherin- $\beta$-catenin interaction was inhibited, and enhanced nuclear translocation of $\beta$-catenin was observed (Hase et al. 2013). The mislocalization of Ecadherin was also observed in an intestinal epithelial cell line that lacked the mu1B subunit, and the ectopic expression of the latter restored the normal distribution of E-cadherin (Mimura et al. 2012). The nuclear translocation of $\beta$-catenin was shown to stimulate the preproliferative $\beta$-catenin/Tcf4 pathway, and Ap1m2 $2^{-/}$mice showed intestinal crypt hyperplasia with villous dysplasia massively enlarged as a result of excessive proliferation of IEC, but the overall length of the small intestine does not seem to be significantly changed. 
L.J. Klunder et al.

Interestingly, although AP-1B is considered to be a regulator of basolateral protein sorting (Fölsch 2005), also resident apical proteins were found missorted in IEC of Ap1m2 $2^{-/}$mice. For example, the resident apical proteins villin and sucrase-isomaltase were mistargeted to the lateral plasma membrane. The apical surface of the IEC developed sparse and disorganized microvilli, whereas ectopic microvillus-like structures developed at the lateral membrane. In accordance, these mice developed digestive and/ or absorptive defects (Hase et al. 2013). In Aplm2 $2^{-/-}$mice, intestinal IgA responses were induced, but the basal-to-apical transcytosis of IgA from the lamina propria to the lumen of the intestine was impaired (Takahashi et al. 2011), possibly reflecting impaired basal sorting of the polymeric IgA receptor. Also in the nematode Caenorhabditis elegans AP-1 was shown to control an apical trafficking pathway and regulate apical polarity and intestinal epithelial morphogenesis (Shafaq-Zadah et al. 2012; Zhang et al. 2012). The role of AP-1B in the delivery of apical proteins in IEC may be explained by the observation that some apical membrane proteins, including sucrase-isomaltase, are transported in distinct vesicular carriers (Jacob and Naim 2001) and are first sorted to the basal surface, from where these are subsequently internalized and transcytosed to the apical brush-border domain of IECs (Hauri 1983; Le Bivic et al. 1990; Meerson et al. 2000). In conclusion, AP-1B is required for the delivery of (at least a subset of ) proteins to the apical surface in IEC and, as a result, controls the function of the intestinal apical brush-border surface.

Ap1m2 $2^{-/-}$mice spontaneously develop colitis (Takahashi et al. 2011). It was proposed that the missorting of cytokine receptors from the basal to the apical surface, the reduced expression of antimicrobial proteins, and the impaired apical release of IgA in these mice resulted in intestinal dysbiosis and increased bacterial translocation from the lumen of the gut into the lamina propria (Takahashi et al. 2011).

These results show the importance of the CRE-associated polarized sorting factor adaptor protein $\mathrm{AP}-1 \mathrm{~B}$ as a crucial player in the establishment of IEC polarity, epithelial homeostasis, and immunity in the gut.

\section{EVOLUTIONARY CONSERVED CELL POLARITY DETERMINING PROTEINS REGULATE EPITHELIAL HOMEOSTASIS, TUMOR SUPPRESSION, AND INNATE IMMUNITY IN THE GUT}

Three evolutionary conserved protein complexes, initially discovered in the nematode C. elegans (Kemphues et al. 1988), play a pivotal role in the development of cell polarity, including mammalian epithelial cell polarity (Rodriguez-Boulan and Macara 2014). These proteins complexes include (1) the Crumbs3/protein associated with tight junctions (PATJ)/protein associated with Lin Seven (Pals) 1 complex, (2) the Partitioning defective (Par)3/Par6/atypical protein kinase $\mathrm{C}$ (aPKC) complex, and (3) the Scribble/Lethal giant larvae (Lgl)/Discs large (Dlg) complex. Many of these proteins are tumor suppressors and therefore link epithelial cell polarity to the maintenance of epithelial homeostasis. These polarity protein complexes have been extensively studied in a variety of polarized cell systems, and much less in the intestine. Nonetheless, as outlined below, the aberrant expression, localization, and/or function of the human orthologs of these proteins have been implicated in defective epithelial homeostasis and immunity in the gut.

\section{The Crumbs3/PATJ/Pals1 Complex}

Crumbs 3 is localized to the apical and subapical area of epithelial cells from the mouse and human intestine (Lemmers et al. 2004). Studies in Caco-2 cells showed that PATJ stabilized the Crumbs 3 complex and regulated the spatial concentration of several components at the border between the apical and lateral domains (Michel et al. 2005). Although PATJ or Pals1-deficient mice have not been reported, Crumbs3-deficient mice show defective intestinal epithelial morphogenesis via its role in apical brush-border organization (Whiteman et al. 2014; Charrier et al. 2015). Of interest, TJs and the barrier function of the intestinal epithelium appeared 
unaffected in Crumbs3-deficient mice (Whiteman et al. 2014).

\section{The Par3/Par6/aPKC Complex}

aPKC is aberrantly expressed in intestinal tissue from individuals with active and inactive inflammatory bowel disease (Wald et al. 2011). A negative correlation has been reported between the expression of active aPKC and local inflammation. Induction of inflammation in mice with dextran-sulfate sodium or treatment with TNF- $\alpha$ was shown to disrupt the Par3/ Par6/aPKC polarity complex and its activity in intestinal epithelial cells via a posttranslational mechanism, which involved the degradation of aPKC as a result of inhibited chaperoning activity of BAG-1M and Hsc/Hsp70 (Mashukova et al. 2011, 2014). Par3 and aPKC were proposed to act as inhibitors of the canonical NF- $\mathrm{KB}$ activation pathway in this way involved in proinflammatory responses (Forteza et al. 2013). Loss of aPKC or Par3 by RNA interference in cultured IEC phenocopied inflammatory signaling, as evidenced by enhanced NF- $\mathrm{KB}$ activity and resultant myosin light chain kinase (MLCK) expression, an enhanced TNF- $\alpha$ response, and enhanced paracellular leakage (Mashukova et al. 2011; Forteza et al. 2013). Genetic variants of Par3 have been associated with coeliac disease and ulcerative colitis in a Dutch cohort (Wapenaar et al. 2008). Reduced expression of Par3 in cultured intestinal epithelial cells was associated with altered expression and assembly of several TJ proteins (Schumann et al. 2012), the latter of which, in turn, have been associated with enhanced paracellular leakage in intestinal inflammatory diseases (Edelblum and Turner 2009; Schulzke et al. 2009), including celiac disease (Schumann et al. 2012), ulcerative colitis (Oshima et al. 2008), and Crohn's disease (Schulzke et al. 2009).

Atypical PKC and Par6B show aberrant localization in IEC of individuals with microvillus inclusion disease carrying MYO5B mutations (Dhekne et al. 2014; Kravtsov et al. 2014; Michaux et al. 2015), which is in agreement with a reported role for apical recycling endosomes in the regulation of the subcellular distribution of these polarity proteins (Golachowska et al. 2010; Dhekne et al. 2014). The mislocalization of aPKC-iota from the subapical domain of IEC was associated with impaired activation of ezrin at the apical surface and consequent impaired brush-border development (Dhekne et al. 2014). Individuals with microvillus inclusion disease do not typically show signs of intestinal inflammation (Cutz et al. 1989), suggesting that the mislocalization of the Par3/Par6/aPKC complex, as such, does not necessarily compromise the intestinal barrier function and immunity in the gut. Further, hypoxic stress signaling resulted in the angiomotin-mediated retention of Par3 and Crumbs3 in intracellular vesicles and prevented these proteins from reaching the apical cell surface. The resulting loss of cell polarity potentiated the response to invasive cues, both in vitro in intestinal epithelial Caco2 cells and in vivo in mice (Mojallal et al. 2014). Par6 was reported to play a role in the directional (i.e., polarized migration of IEC as part of the intestinal wound healing response [Koch et al. 2009]).

Taken together, both the expression and localization of members of the Par3/Par6/aPKC polarity complex are important, albeit in different ways, for intestinal epithelial functions. The maintenance of proper expression levels of members of the Par3/Par6/aPKC polarity complex appears important for the barrier function of the intestinal epithelium and thereby for innate immunity, and reduced expression and/or activity of aPKC and Par3 likely contribute to epithelial barrier dysregulation in inflammatory bowel diseases (Mashukova et al. 2011). By contrast, the maintenance of the proper subcellular localization of members of the Par3/Par6/ aPKC complex appears important for apical brush-border membrane development and preventing carcinogenesis but, based on the available data, not for the regulation of immunity in the intestine.

\section{The Scribble/Lgl/Dlg Complex}

The expression of Scribble was reported to be downregulated in inflamed colonic mucosa of active Crohn's disease (Ivanov et al. 2010). RNA 
L.J. Klunder et al.

interference studies in human intestinal cell lines showed that Scribble, independently of its interaction with $\mathrm{LgL}$ and $\mathrm{Dlg}$, regulated the epithelial barrier function via its effects on the de novo assembly and reassembly of tight junctions (Ivanov et al. 2010). The depletion of Scribble did not affect E-cadherin-based adherens junctions (Ivanov et al. 2010). In vitro exposure IEC to interferon $\gamma$ (IFN- $\gamma$ ), a key proinflammatory cytokine in inflammatory bowel disease (Neurath 2014), resulted in the mislocalization of Scribble away from the tight junctions, suggesting that IFN- $\gamma$-induced depletion of Scribble from tight junctions may contribute to the breakdown of the epithelial barrier during intestinal inflammation or impair the recovery of the intestinal epithelial barrier during epithelial restitution (Ivanov et al. 2010). Inflammatory bowel disease is an important risk factor for the development of colorectal cancer (Francescone et al. 2015). Notably, changes in the expression patterns of Scribble and Dgl are correlated with loss of colon tissue architecture during malignant progression (Gardiol et al. 2006). Further, Scribble was found to accumulate in colorectal neoplasia in association with an altered distribution of $\beta$-catenin (Kamei et al. 2007). In addition to Scribble, the human ortholog of the Drosophila melanogaster tumor suppressor gene Lgl, was found to be reduced in colorectal tumor samples in a stage-dependent manner (Schimanski et al. 2005), and the human ortholog of D. melanogaster Discs Large (Dlg) has been associated with inflammatory bowel diseases (Stoll et al. 2004; Weersma et al. 2009), albeit debated (Büning et al. 2006), and colon cancer (Subbaiah et al. 2012). Altogether, these findings suggest a role for the cell polarity-regulating Scribble/Lgl/Dlg complex in the pathogenesis of inflammatory bowel disease (Ivanov et al. 2010) and in colon carcinogenesis (Kamei et al. 2007).

\section{CONCLUDING REMARKS}

The polarity of IEC is essential to properly balance communications with the microbiota and immune cells at opposite sides of the epithelial barrier and, in this way, ensures effective im- mune responses that allow a full restoration of intestinal tissue function when inflammation is resolved. Defects in the mechanisms that control the polarity of IEC are associated with impaired epithelial homeostasis, impaired innate immunity and inflammatory bowel disease, and colon carcinogenesis.

Particularly the apical brush-border membrane and the recycling endosomal system appear as prominent regulators of epithelial homeostasis, tumor suppression, and immunity in the gut. Interestingly, components of both the ARE system (Rab11a, Rab8, Rab25, myo$\sin -\mathrm{Vb}$ ) and the CRE system (AP-1B) appear to be involved in epithelial homeostasis and immunity in the intestine, and further research is warranted to elucidate how these proteins and the different endosomal compartments cooperate.

Rab8 and AP-1B were initially reported as regulators of basolateral protein sorting and trafficking in cultured Madin-Darby canine kidney cells (Huber et al. 1993; Ang et al. 2003; Fölsch 2005; Henry and Sheff 2008). Intestine-specific deletion these proteins, however, have implicated these proteins (also) in the regulation of apical protein sorting and/or trafficking (Sato et al. 2007, 2014; Takahashi et al. 2011). These results suggest that the function of these proteins may differ between in vitro and in vivo contexts, or may be different in intestinal epithelial cells. Regardless, the study of these proteins in IEC have shed new light onto their function in cell polarity.

Notably, although Rab11a, Rab8, and Rab25 all have been implicated in the regulation of intracellular trafficking via the apical recycling endosomes and all can interact with myosin $\mathrm{Vb}$, the individual depletion of these proteins from the intestine in mice gives rise to only partly overlapping and often distinctive effects on intracellular protein expression and distribution, epithelial homeostasis, and immunity in the intestine. This may indicate that the apical recycling endosome and/or its molecular components display extensive functional heterogeneity with regard to the regulation of nutrient absorption, epithelial homeostasis and tumor suppression, and immunity. A caveat, however, is the nonuniformity of read-out between the 
different knock-out mice as reported in the different studies. For example, TLR mislocalization has been studied in the mouse intestine depleted of Rab11a, but not in the mouse intestine depleted of Rab8, Rab25, or Myosin Vb (or at least not reported). A more comprehensive and uniform read-out of effects is, therefore, needed to obtain better insight into the roles of the apical recycling endosomal system and its regulators in the different processes.

Along the same lines, further studies are required to determine the organization and function of the endosomal system, expression, and function of cell polarity-determining proteins, and immunity-regulating cell-surface proteins (1) along the vertical (crypt-to-villus) axis (e.g., Lindfors et al. 2001; Xiong et al. 2016), (2) along the horizontal (from duodenum to colon) axis of the intestine (Middendorp et al. 2014), and (3) as a function of age (Man et al. 2014; Soenen et al. 2016), and to determine how variations herein contribute to the regulation of intestinal epithelial homeostasis and immunity.

An intriguing finding is that apical surface microvilli appear to produce extracellular vesicles that can interfere with bacteria in the lumen of the gut. It will be of interest to determine the consequences of microvillus atrophy, as a result of different causes, on the regulation of immunity in the intestine. Further, it will be of interest to determine the potential contribution of apical microvilli-derived vesicles to normal intestinal epithelial homeostasis and tumor suppression.

Perturbed immunity in the intestine and the initiation and/or progression of colon carcinogenesis have been proposed to be associated. The observation that inhibition or depletion of some polarity-determining proteins give rise to both inflammation and colon cancer are in support of this. However, in some cases defects in either immunity or tumor suppression are observed, underscoring that these events may not be necessarily linked, and offer tools to further investigate their interrelationship.

In conclusion, IEC polarity is at the heart of epithelial homeostasis and immunity in the intestine. Defects in the mechanisms that underlie intestinal epithelial cell polarity are functionally associated with inflammatory bowel disease and colon carcinogenesis, of which the pathogenesis is not fully understood and for which cures do not exist. The further elucidation of the mechanisms that underlie IEC polarity will contribute to our understanding of the pathogenesis of these diseases and is expected to identify molecular targets that may be exploited for therapeutic interventions.

\section{REFERENCES}

Ameen NA, Salas PJ. 2000. Microvillus inclusion disease: A genetic defect affecting apical membrane protein traffic in intestinal epithelium. Traffic 1: 76-83.

Ang AL, Fölsch H, Koivisto U-M, Pypaert M, Mellman I. 2003. The Rab8 GTPase selectively regulates AP-1Bdependent basolateral transport in polarized MadinDarby canine kidney cells. J Cell Biol 163: 339-350.

Bay AEP, Schreiner R, Rodriguez-Boulan E. 2015. Structural and functional analysis of endosomal compartments in epithelial cells. Methods Cell Biol 130: 271-288.

Bruurs LJM, Donker L, Zwakenberg S, Zwartkruis FJ, Begthel H, Knisely AS, Posthuma G, van de Graaf SFJ, Paulusma CC, Bos JL. 2015. ATP8B1-mediated spatial organization of Cdc42 signaling maintains singularity during enterocyte polarization. J Cell Biol 210: 10551063.

Bryant DM, Datta A, Rodríguez-Fraticelli AE, Peränen J, Martín-Belmonte F, Mostov KE. 2010. A molecular network for de novo generation of the apical surface and lumen. Nat Cell Biol 12: 1035-1045.

Büning C, Geerdts L, Fiedler T, Gentz E, Pitre G, Reuter W, Luck W, Buhner S, Molnar T, Nagy F, et al. 2006. DLG5 variants in inflammatory bowel disease. Am J Gastroenterol 101: 786-792.

Cartón-García F, Overeem AW, Nieto R, Bazzocco S, Dopeso H, Macaya I, Bilic J, Landolfi S, HernandezLosa J, Schwartz S, et al. 2015. Myo5b knockout mice as a model of microvillus inclusion disease. Sci Rep 5: 12312.

Casaletto JB, Saotome I, Curto M, McClatchey AI. 2011. Ezrin-mediated apical integrity is required for intestina homeostasis. Proc Natl Acad Sci 108: 11924-11929.

Casanova JE, Wang X, Kumar R, Bhartur SG, Navarre J, Woodrum JE, Altschuler Y, Ray GS, Goldenring JR. 1999. Association of Rab25 and Rab1la with the apical recycling system of polarized Madin-Darby canine kidney cells. Mol Biol Cell 10: 47-61.

Caswell PT, Spence HJ, Parsons M, White DP, Clark K, Cheng KW, Mills GB, Humphries MJ, Messent AJ, Anderson KI, et al. 2007. Rab25 associates with $\alpha 5 \beta 1$ integrin to promote invasive migration in $3 \mathrm{D}$ microenvironments. Dev Cell 13: 496-510.

Caswell PT, Chan M, Lindsay AJ, McCaffrey MW, Boettiger D, Norman JC. 2008. Rab-coupling protein coordinates recycling of $\alpha 5 \beta 1$ integrin and EGFR1 to promote cell 
L.J. Klunder et al.

migration in 3D microenvironments. J Cell Biol 183: 143-155.

Charrier LE, Loie E, Laprise P. 2015. Mouse Crumbs3 sustains epithelial tissue morphogenesis in vivo. Sci Rep 5: 17699.

Chen T, Hubbard A, Murtazina R, Price J, Yang J, Cha B, Sarker R, Donowitz M. 2014. Myosin VI mediates the movement of NHE3 down the microvillus in intestinal epithelial cells. J Cell Sci 127: 3535-3545.

Crawley SW, Mooseker MS, Tyska MJ. 2014. Shaping the intestinal brush border. J Cell Biol 207: 441-451.

Cutz E, Rhoads JM, Drumm B, Sherman PM, Durie PR, Forstner GG. 1989. Microvillus inclusion disease: An inherited defect of brush-border assembly and differentiation. N Engl J Med 320: 646-651.

Das S, Yu S, Sakamori R, Vedula P, Feng Q, Flores J, Hoffman A, Fu J, Stypulkowski E, Rodriguez A, et al. 2015. Rab8a vesicles regulate Wnt ligand delivery and Paneth cell maturation at the intestinal stem cell niche. Dev Camb Engl 142: $2147-2162$.

Dhekne HS, Hsiao N-H, Roelofs P, Kumari M, Slim CL, Rings EHHM, van Ijzendoorn SCD. 2014. Myosin Vb and Rab1la regulate phosphorylation of ezrin in enterocytes. J Cell Sci 127: 1007-1017.

Edelblum KL, Turner JR. 2009. The tight junction in inflammatory disease: Communication breakdown. Curr Opin Pharmacol 9: 715-720.

Fölsch H. 2005. The building blocks for basolateral vesicles in polarized epithelial cells. Trends Cell Biol 15: 222-228.

Forteza R, Wald FA, Mashukova A, Kozhekbaeva Z, Salas PJ. 2013. Par-complex aPKC and Par3 cross-talk with innate immunity NF-кB pathway in epithelial cells. Biol Open 2: 1264-1269.

Francescone R, Hou V, Grivennikov SI. 2015. Cytokines, IBD, and colitis-associated cancer. Inflamm Bowel Dis 21: $409-418$.

Gardiol D, Zacchi A, Petrera F, Stanta G, Banks L. 2006. Human discs large and scrib are localized at the same regions in colon mucosa and changes in their expression patterns are correlated with loss of tissue architecture during malignant progression. Int J Cancer J Int Cancer 119: $1285-1290$

Ghadimi D, de Vrese M, Heller KJ, Schrezenmeir J. 2010. Effect of natural commensal-origin DNA on toll-like receptor 9 (TLR9) signaling cascade, chemokine IL-8 expression, and barrier integrity of polarized intestinal epithelial cells. Inflamm Bowel Dis 16: 410-427.

Giepmans BNG, van Ijzendoorn SCD. 2009. Epithelial cellcell junctions and plasma membrane domains. Biochim Biophys Acta 1788: 820-831.

Golachowska MR, Hoekstra D, van IJzendoorn SCD. 2010. Recycling endosomes in apical plasma membrane domain formation and epithelial cell polarity. Trends Cell Biol 20: 618-626.

Golachowska MR, van Dael CML, Keuning H, Karrenbeld A, Hoekstra D, Gijsbers CFM, Benninga MA, Rings EHHM, van Ijzendoorn SCD. 2012. MYO5B mutations in patients with microvillus inclusion disease presenting with transient renal Fanconi syndrome. J Pediatr Gastroenterol Nutr 54: 491-498.
Goldenring JR, Nam KT. 2011. Rab25 as a tumour suppressor in colon carcinogenesis. Br J Cancer 104: 33-36.

Hase K, Nakatsu F, Ohmae M, Sugihara K, Shioda N, Takahashi D, Obata Y, Furusawa Y, Fujimura Y, Yamashita T, et al. 2013. AP-1B-mediated protein sorting regulates polarity and proliferation of intestinal epithelial cells in mice. Gastroenterology 145: 625-635.

Hauri HP. 1983. Biosynthesis and transport of plasma membrane glycoproteins in the rat intestinal epithelial cell: Studies with sucrase-isomaltase. Ciba Found Symp 95: $132-163$.

Hegan PS, Giral H, Levi M, Mooseker MS. 2012. Myosin VI is required for maintenance of brush border structure, composition, and membrane trafficking functions in the intestinal epithelial cell. Cytoskeleton (Hoboken) 69: 235251.

Henry L, Sheff DR. 2008. Rab8 regulates basolateral secretory, but not recycling, traffic at the recycling endosome. Mol Biol Cell 19: 2059-2068.

Huber LA, Pimplikar S, Parton RG, Virta H, Zerial M, Simons K. 1993. Rab8, a small GTPase involved in vesicular traffic between the TGN and the basolateral plasma membrane. J Cell Biol 123: 35-45.

Hughson EJ, Hopkins CR. 1990. Endocytic pathways in polarized Caco-2 cells: Identification of an endosomal compartment accessible from both apical and basolateral surfaces. J Cell Biol 110: 337-348.

Ivanov AI, Young C, Den Beste K, Capaldo CT, Humbert PO, Brennwald P, Parkos CA, Nusrat A. 2010. Tumor suppressor scribble regulates assembly of tight junctions in the intestinal epithelium. Am J Pathol 176: 134-145.

Jacob R, Naim HY. 2001. Apical membrane proteins are transported in distinct vesicular carriers. Curr Biol CB 11: $1444-1450$.

Jacquemet G, Green DM, Bridgewater RE, von Kriegsheim A, Humphries MJ, Norman JC, Caswell PT. 2013. RCPdriven $\alpha 5 \beta 1$ recycling suppresses $\mathrm{Rac}$ and promotes RhoA activity via the RacGAP1-IQGAP1 complex. $J$ Cell Biol 202: 917-935.

Jaffe AB, Kaji N, Durgan J, Hall A. 2008. Cdc42 controls spindle orientation to position the apical surface during epithelial morphogenesis. J Cell Biol 183: 625-633.

Kamei Y, Kito K, Takeuchi T, Imai Y, Murase R, Ueda N, Kobayashi N, Abe Y. 2007. Human scribble accumulates in colorectal neoplasia in association with an altered distribution of $\beta$-catenin. Hum Pathol 38: 1273-1281.

Kemphues KJ, Priess JR, Morton DG, Cheng NS. 1988. Identification of genes required for cytoplasmic localization in early C. elegans embryos. Cell 52: 311-320.

Kersting S, Bruewer M, Schuermann G, Klotz A, Utech M, Hansmerten M, Krieglstein CF, Senninger N, Schulzke JD, Naim HY, et al. 2004. Antigen transport and cytoskeletal characteristics of a distinct enterocyte population in inflammatory bowel diseases. Am J Pathol 165: 425-437.

Khurana S, George SP. 2008. Regulation of cell structure and function by actin-binding proteins: Villin's perspective. FEBS Lett 582: 2128-2139.

Knowles BC, Roland JT, Krishnan M, Tyska MJ, Lapierre LA, Dickman PS, Goldenring JR, Shub MD. 2014. Myosin Vb uncoupling from RAB8A and RAB11A elicits microvillus inclusion disease. J Clin Invest 124: 2947-2962. 
Knowles BC, Weis VG, Yu S, Roland JT, Williams JA, Alvarado GS, Lapierre LA, Shub MD, Gao N, Goldenring JR. 2015. Rab1la regulates Syntaxin 3 localization and microvillus assembly in enterocytes. J Cell Sci 128: 1617 1626.

Koch S, Capaldo CT, Samarin S, Nava P, Neumaier I, Skerra A, Sacks DB, Parkos CA, Nusrat A. 2009. Dkk-1 inhibits intestinal epithelial cell migration by attenuating directional polarization of leading edge cells. Mol Biol Cell 20: 4816-4825.

Kravtsov D, Mashukova A, Forteza R, Rodriguez MM, Ameen NA, Salas PJ. 2014. Myosin 5b loss of function leads to defects in polarized signaling: Implication for microvillus inclusion disease pathogenesis and treatment. Am J Physiol Gastrointest Liver Physiol 307: G992-G1001.

Krishnan M, Lapierre LA, Knowles BC, Goldenring JR. 2013. Rab25 regulates integrin expression in polarized colonic epithelial cells. Mol Biol Cell 24: 818-831.

Kühne H, Hause G, Grundmann SM, Schutkowski A, Brandsch C, Stangl GI. 2015. Vitamin D receptor knockout mice exhibit elongated intestinal microvilli and increased ezrin expression. Nutr Res 36: 184-192.

Le Bivic A, Quaroni A, Nichols B, Rodriguez-Boulan E. 1990. Biogenetic pathways of plasma membrane proteins in Caco-2, a human intestinal epithelial cell line. J Cell Biol 111: 1351-1361.

Lee J, Mo JH, Katakura K, Alkalay I, Rucker AN, Liu YT, Lee HK, Shen C, Cojocaru G, Shenouda S, et al. 2006. Maintenance of colonic homeostasis by distinctive apical TLR9 signalling in intestinal epithelial cells. Nat Cell Biol 8: 1327-1336.

Lemmers C, Michel D, Lane-Guermonprez L, Delgrossi M-H, Médina E, Arsanto JP, Le Bivic A. 2004. CRB3 binds directly to Par6 and regulates the morphogenesis of the tight junctions in mammalian epithelial cells. Mol Biol Cell 15: 1324-1333.

Lindfors K, Halttunen T, Kainulainen H, Mäki M. 2001. Differentially expressed CC3/TIP30 and rab11 along in vivo and in vitro intestinal epithelial cell crypt-villus axis. Life Sci 69: 1363-1372.

Man AL, Gicheva N, Nicoletti C. 2014. The impact of ageing on the intestinal epithelial barrier and immune system. Cell Immunol 289: 112-118.

Marchiando AM, Graham WV, Turner JR. 2010. Epithelial barriers in homeostasis and disease. Annu Rev Pathol 5: 119-144.

Marques R, Boneca IG. 2011. Expression and functional importance of innate immune receptors by intestinal epithelial cells. Cell Mol Life Sci 68: 3661-3673.

Mashukova A, Wald FA, Salas PJ. 2011. Tumor necrosis factor $\alpha$ and inflammation disrupt the polarity complex in intestinal epithelial cells by a posttranslational mechanism. Mol Cell Biol 31: 756-765.

Mashukova A, Kozhekbaeva Z, Forteza R, Dulam V, Figueroa Y, Warren R, Salas PJ. 2014. The BAG-1 isoform BAG$1 \mathrm{M}$ regulates keratin-associated Hsp70 chaperoning of aPKC in intestinal cells during activation of inflammatory signaling. J Cell Sci 127: 3568-3577.

Matter K, Aijaz S, Tsapara A, Balda MS. 2005. Mammalian tight junctions in the regulation of epithelial differentiation and proliferation. Curr Opin Cell Biol 17: 453-458.
Mazzolini R, Dopeso H, Mateo-Lozano S, Chang W, Rodrigues P, Bazzocco S, Alazzouzi H, Landolfi S, HernándezLosa J, Andretta E, et al. 2012. Brush border myosin Ia has tumor suppressor activity in the intestine. Proc Natl Acad Sci 109: 1530-1535.

McConnell RE, Tyska MJ. 2007. Myosin-1a powers the sliding of apical membrane along microvillar actin bundles. $J$ Cell Biol 177: 671-681.

McConnell RE, Higginbotham JN, Shifrin DA, Tabb DL, Coffey RJ, Tyska MJ. 2009. The enterocyte microvillus is a vesicle-generating organelle. J Cell Biol 185: 1285-1298.

Meerson NR, Bello V, Delaunay JL, Slimane TA, Delautier D, Lenoir C, Trugnan G, Maurice M. 2000. Intracellular traffic of the ecto-nucleotide pyrophosphatase/phosphodiesterase NPP3 to the apical plasma membrane of MDCK and Caco-2 cells: Apical targeting occurs in the absence of N-glycosylation. J Cell Sci 113: 4193-4202.

Melendez J, Liu M, Sampson L, Akunuru S, Han X, Vallance J, Witte D, Shroyer N, Zheng Y. 2013. Cdc42 coordinates proliferation, polarity, migration, and differentiation of small intestinal epithelial cells in mice. Gastroenterology 145: $808-819$.

Michaux G, Massey-Harroche D, Nicolle O, Rabant M, Brousse N, Goulet O, Bivic AL, Ruemmele FM. 2015. The localisation of the apical Par/Cdc42 polarity module is specifically affected in microvillus inclusion disease. Biol Cell 108: 19-28.

Michel D, Arsanto J-P, Massey-Harroche D, Béclin C, Wijnholds J, Le Bivic A. 2005. PATJ connects and stabilizes apical and lateral components of tight junctions in human intestinal cells. J Cell Sci 118: 4049-4057.

Middendorp S, Schneeberger K, Wiegerinck CL, Mokry M, Akkerman RDL, van Wijngaarden S, Clevers H, Nieuwenhuis EES. 2014. Adult stem cells in the small intestine are intrinsically programmed with their location-specific function. Stem Cells 32: 1083-1091.

Mimura M, Masuda A, Nishiumi S, Kawakami K, Fujishima Y, Yoshie T, Mizuno S, Miki I, Ohno H, Hase K, et al. 2012. AP1B plays an important role in intestinal tumorigenesis with the truncating mutation of an APC gene. Int J Cancer J Int Cancer 130: 1011-1020.

Mitra S, Cheng KW, Mills GB. 2012. Rab25 in cancer: A brief update. Biochem Soc Trans 40: 1404-1408.

Moidunny S, Vinet J, Wesseling E, Bijzet J, Shieh C-H, van Ijzendoorn SCD, Bezzi P, Boddeke HWGM, Biber K. 2012. Adenosine A2B receptor-mediated leukemia inhibitory factor release from astrocytes protects cortical neurons against excitotoxicity. J Neuroinflammation 9: 198.

Mojallal M, Zheng Y, Hultin S, Audebert S, van Harn T, Johnsson P, Lenander C, Fritz N, Mieth C, Corcoran M, et al. 2014. AmotL2 disrupts apical-basal cell polarity and promotes tumour invasion. Nat Commun 5: 4557.

Nam KT, Lee H-J, Smith JJ, Lapierre LA, Kamath VP, Chen X, Aronow BJ, Yeatman TJ, Bhartur SG, Calhoun BC, et al. 2010. Loss of Rab25 promotes the development of intestinal neoplasia in mice and is associated with human colorectal adenocarcinomas. J Clin Invest 120: 840-849.

Neurath MF. 2014. Cytokines in inflammatory bowel disease. Nat Rev Immunol 14: 329-342.

Oshima T, Miwa H, Joh T. 2008. Changes in the expression of claudins in active ulcerative colitis. J Gastroenterol Hepatol 23: S146-S150. 
L.J. Klunder et al.

Overeem AW, Posovszky C, Rings EHMM, Giepmans BNG, van IJzendoorn SCD. 2016. The role of enterocyte defects in the pathogenesis of congenital diarrheal disorders. Dis Model Mech 9: 1-12.

Pasparakis M. 2009. Regulation of tissue homeostasis by NF$\kappa \mathrm{B}$ signalling: Implications for inflammatory diseases. Nat Rev Immunol 9: 778-788.

Paul NR, Allen JL, Chapman A, Morlan-Mairal M, Zindy E, Jacquemet G, Fernandez del Ama L, Ferizovic N, Green DM, Howe JD, et al. 2015. $\alpha 5 \beta 1$ integrin recycling promotes Arp2/3-independent cancer cell invasion via the formin FHOD3. J Cell Biol 210: 1013-1031.

Perret E, Lakkaraju A, Deborde S, Schreiner R, RodriguezBoulan E. 2005. Evolving endosomes: How many varieties and why? Curr Opin Cell Biol 17: 423-434.

Pinson KI, Dunbar L, Samuelson L, Gumucio DL. 1998. Targeted disruption of the mouse villin gene does not impair the morphogenesis of microvilli. Dev Dyn 211: 109-121.

Poelstra K, Bakker WW, Klok PA, Hardonk MJ, Meijer DK. 1997. A physiologic function for alkaline phosphatase: endotoxin detoxification. Lab Investig J Tech Methods Pathol 76: 319-327.

Pope JL, Bhat AA, Sharma A, Ahmad R, Krishnan M, Washington MK, Beauchamp RD, Singh AB, Dhawan P. 2014 Claudin-1 regulates intestinal epithelial homeostasis through the modulation of Notch-signalling. Gut 63: 622-634.

Rodriguez-Boulan E, Macara IG. 2014. Organization and execution of the epithelial polarity programme. Nat Rev Mol Cell Biol 15: 225-242.

Rossi O, Karczewski J, Stolte EH, Brummer RJM, van Nieuwenhoven MA, Meijerink M, van Neerven JRJ, van Ijzendoorn SCD, van Baarlen P, Wells JM. 2013. Vectorial secretion of interleukin-8 mediates autocrine signalling in intestinal epithelial cells via apically located CXCR1. BMC Res Notes 6: 431.

Sakamori R, Das S, Yu S, Feng S, Stypulkowski E, Guan Y, Douard V, Tang W, Ferraris RP, Harada A, et al. 2012. Cdc42 and Rab8a are critical for intestinal stem cell division, survival, and differentiation in mice. J Clin Invest 122: $1052-1065$.

Saotome I, Curto M, McClatchey AI. 2004. Ezrin is essential for epithelial organization and villus morphogenesis in the developing intestine. Dev Cell 6: 855-864.

Sato T, Mushiake S, Kato Y, Sato K, Sato M, Takeda N, Ozono K, Miki K, Kubo Y, Tsuji A, et al. 2007. The Rab8 GTPase regulates apical protein localization in intestinal cells. Nature 448: 366-369.

Sato T, Iwano T, Kunii M, Matsuda S, Mizuguchi R, Jung Y, Hagiwara H, Yoshihara Y, Yuzaki M, Harada R, et al. 2014 Rab8a and Rab8b are essential for several apical transport pathways but insufficient for ciliogenesis. J Cell Sci 127: 422-431.

Schimanski CC, Schmitz G, Kashyap A, Bosserhoff AK, Bataille F, Schäfer SC, Lehr HA, Berger MR, Galle PR, Strand S, et al. 2005. Reduced expression of Hugl-1, the human homologue of Drosophila tumour suppressor gene $\operatorname{lgl}$, contributes to progression of colorectal cancer. Oncogene 24: 3100-3109.

Schneeberger K, Vogel GF, Teunissen H, van Ommen DD, Begthel H, El Bouazzaoui L, van Vugt AHM, Beekman
JM, Klumperman J, Müller T, et al. 2015. An inducible mouse model for microvillus inclusion disease reveals a role for myosin $\mathrm{Vb}$ in apical and basolateral trafficking. Proc Natl Acad Sci 112: 12408-12413.

Schulzke JD, Ploeger S, Amasheh M, Fromm A, Zeissig S, Troeger H, Richter J, Bojarski C, Schumann M, Fromm M. 2009. Epithelial tight junctions in intestinal inflammation. Ann NY Acad Sci 1165: 294-300.

Schumann M, Günzel D, Buergel N, Richter JF, Troeger H, May C, Fromm A, Sorgenfrei D, Daum S, Bojarski C, et al. 2012. Cell polarity-determining proteins Par-3 and PP-1 are involved in epithelial tight junction defects in coeliac disease. Gut 61: 220-228.

Shafaq-Zadah M, Brocard L, Solari F, Michaux G. 2012. AP1 is required for the maintenance of apico-basal polarity in the C. elegans intestine. Development 139: 2061-2070.

Shifrin DA, Tyska MJ. 2012. Ready. . .aim. . fire into the lumen: A new role for enterocyte microvilli in gut host defense. Gut Microbes 3: 460-462.

Shifrin DA, McConnell RE, Nambiar R, Higginbotham JN, Coffey RJ, Tyska MJ. 2012. Enterocyte microvillus-derived vesicles detoxify bacterial products and regulate epithelial-microbial interactions. Curr Biol CB 22: 627-631.

Singh AB, Dhawan P. 2015. Claudins and cancer: Fall of the soldiers entrusted to protect the gate and keep the barrier intact. Semin Cell Dev Biol 42: 58-65.

Sobajima T, Yoshimura S-I, Iwano T, Kunii M, Watanabe M, Atik N, Mushiake S, Morii E, Koyama Y, Miyoshi E, et al. 2014a. Rab11a is required for apical protein localisation in the intestine. Biol Open 4: 86-94.

Sobajima T, Yoshimura S-I, Iwano T, Kunii M, Watanabe M, Atik N, Mushiake S, Morii E, Koyama Y, Miyoshi E, et al. 2014b. Rab1la is required for apical protein localisation in the intestine. Biol Open 4: 86-94.

Soenen S, Rayner CK, Jones KL, Horowitz M. 2016. The ageing gastrointestinal tract. Curr Opin Clin Nutr Metab Care 19: 12-18.

Solaymani-Mohammadi S, Singer SM. 2013. Regulation of intestinal epithelial cell cytoskeletal remodeling by cellular immunity following gut infection. Mucosal Immunol 6: $369-378$.

Stoll M, Corneliussen B, Costello CM, Waetzig GH, Mellgard B, Koch WA, Rosenstiel P, Albrecht M, Croucher PJP, Seegert D, et al. 2004. Genetic variation in DLG5 is associated with inflammatory bowel disease. Nat Genet 36: 476-480.

Stow JL, Murray RZ. 2013. Intracellular trafficking and secretion of inflammatory cytokines. Cytokine Growth Factor Rev 24: 227-239.

Subbaiah VK, Narayan N, Massimi P, Banks L. 2012. Regulation of the DLG tumor suppressor by $\beta$-catenin. Int $J$ Cancer J Int Cancer 131: 2223-2233.

Szperl AM, Golachowska MR, Bruinenberg M, Prekeris R, Thunnissen A-MWH, Karrenbeld A, Dijkstra G, Hoekstra D, Mercer D, Ksiazyk J, et al. 2011. Functional characterization of mutations in the myosin $\mathrm{Vb}$ gene associated with microvillus inclusion disease. J Pediatr Gastroenterol Nutr 52: 307-313.

Takahashi D, Hase K, Kimura S, Nakatsu F, Ohmae M, Mandai Y, Sato T, Date Y, Ebisawa M, Kato T, et al. 2011. The 
epithelia-specific membrane trafficking factor AP-1B controls gut immune homeostasis in mice. Gastroenterology 141: 621-632.

Tuin A, Poelstra K, de Jager-Krikken A, Bok L, Raaben W, Velders MP, Dijkstra G. 2009. Role of alkaline phosphatase in colitis in man and rats. Gut 58: 379-387.

Tyska MJ, Mooseker MS. 2004. A role for myosin-1A in the localization of a brush border disaccharidase. J Cell Biol 165: 395-405.

Tyska MJ, Mackey AT, Huang JD, Copeland NG, Jenkins NA, Mooseker MS. 2005. Myosin-1a is critical for normal brush border structure and composition. Mol Biol Cell 16: $2443-2457$.

Tzaban S, Massol RH, Yen E, Hamman W, Frank SR, Lapierre LA, Hansen SH, Goldenring JR, Blumberg RS, Lencer WI. 2009. The recycling and transcytotic pathways for IgG transport by FcRn are distinct and display an inherent polarity. J Cell Biol 185: 673-684.

Ubelmann F, Chamaillard M, El-Marjou F, Simon A, Netter J, Vignjevic D, Nichols BL, Quezada-Calvillo R, Grandjean T, Louvard D, et al. 2013. Enterocyte loss of polarity and gut wound healing rely upon the F-actinsevering function of villin. Proc Natl Acad Sci 110: E1380-E1389.

van der Wouden JM, Maier O, van IJzendoorn SCD, Hoekstra D. 2003. Membrane dynamics and the regulation of epithelial cell polarity. Int Rev Cytol 226: 127-164.

Wald FA, Forteza R, Diwadkar-Watkins R, Mashukova A, Duncan R, Abreu MT, Salas PJ. 2011. Aberrant expression of the polarity complex atypical PKC and non-muscle myosin IIA in active and inactive inflammatory bowel disease. Virchows Arch Int J Pathol 459: 331-338.

Wang X, Tully O, Ngo B, Zitin M, Mullin JM. 2011. Epithelial tight junctional changes in colorectal cancer tissues. ScientificWorldJournal 11: 826-841.

Wapenaar MC, Monsuur AJ, van Bodegraven AA, Weersma RK, Bevova MR, Linskens RK, Howdle P, Holmes G, Mulder CJ, Dijkstra G, et al. 2008. Associations with tight junction genes PARD3 and MAGI2 in Dutch patients
Mechanisms of Cell Polarity in the Intestine

point to a common barrier defect for coeliac disease and ulcerative colitis. Gut 57: 463-467.

Weersma RK, Stokkers PCF, van Bodegraven AA, van Hogezand RA, Verspaget HW, de Jong DJ, van der Woude CJ, Oldenburg B, Linskens RK, Festen EaM, et al. 2009. Molecular prediction of disease risk and severity in a large Dutch Crohn's disease cohort. Gut 58: 388-395.

Weis GV, Knowles BC, Choi E, Goldstein AE, Williams JA, Manning EH, Roland JT, Lapierre LA, Goldenring JR. 2016. Loss of MYO5B in mice recapitulates microvillus inclusion disease and reveals an apical trafficking pathway distinct to neonatal duodenum. Cell Mol Gastroenterol Hepatol 2: 131-157.

Weisz OA, Rodriguez-Boulan E. 2009. Apical trafficking in epithelial cells: Signals, clusters and motors. J Cell Sci 122: 4253-4266.

Wells JM, Rossi O, Meijerink M, van Baarlen P. 2011. Epithelial crosstalk at the microbiota-mucosal interface. Proc Natl Acad Sci 108: 4607-4614.

Whiteman EL, Fan S, Harder JL, Walton KD, Liu C-J, Soofi A, Fogg VC, Hershenson MB, Dressler GR, Deutsch GH, et al. 2014. Crumbs3 is essential for proper epithelial development and viability. Mol Cell Biol 34: 43-56.

Xiong X, Yang H, Hu X, Wang X, Li B, Long L, Li T, Wang J, Hou Y, Wu G, et al. 2016. Differential proteome analysis along jejunal crypt-villus axis in piglets. Front Biosci Landmark Ed 21: 343-363.

Xu S, Zhou F, Tao J, Song L, Ng SC, Wang X, Chen L, Yi F, Ran Z, Zhou R, et al. 2014. Exome sequencing identifies DLG1 as a novel gene for potential susceptibility to Crohn's disease in a Chinese family study. PloS ONE 9: e99807.

Yu S, Nie Y, Knowles B, Sakamori R, Stypulkowski E, Patel C, Das S, Douard V, Ferraris RP, Bonder EM, et al. 2014. TLR sorting by Rab11 endosomes maintains intestinal epithelial-microbial homeostasis. EMBO J 33: 1882-1895.

Zhang H, Kim A, Abraham N, Khan LA, Hall DH, Fleming JT, Gobel V. 2012. Clathrin and AP-1 regulate apical polarity and lumen formation during C. elegans tubulogenesis. Dev Camb Engl 139: 2071-2083. 


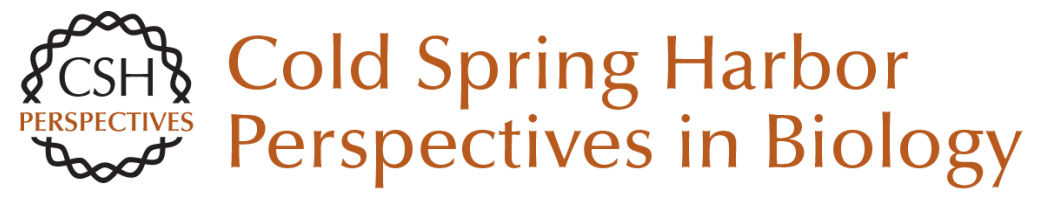

\section{Mechanisms of Cell Polarity-Controlled Epithelial Homeostasis and Immunity in the Intestine}

Leon J. Klunder, Klaas Nico Faber, Gerard Dijkstra and Sven C.D. van IJzendoorn

Cold Spring Harb Perspect Biol 2017; doi: 10.1101/cshperspect.a027888 originally published online February 17, 2017

\section{Subject Collection Cell Polarity}

Regulation of Cell Polarity by Exocyst-Mediated

Trafficking

Noemi Polgar and Ben Fogelgren

Phosphoinositides and Membrane Targeting in

Cell Polarity

Gerald R. Hammond and Yang Hong

Trafficking lon Transporters to the Apical

Membrane of Polarized Intestinal Enterocytes Amy Christine Engevik and James R. Goldenring

Signaling Networks in Epithelial Tube Formation Ilenia Bernascone, Mariam Hachimi and Fernando Martin-Belmonte

Making Heads or Tails of It: Cell-Cell Adhesion in Cellular and Supracellular Polarity in Collective Migration Jan-Hendrik Venhuizen and Mirjam M. Zegers

Laminins in Epithelial Cell Polarization: Old

Questions in Search of New Answers

Karl S. Matlin, Satu-Marja Myllymäki and Aki Manninen

Epithelial Morphogenesis during Liver

Development

Naoki Tanimizu and Toshihiro Mitaka
The Crumbs3 Polarity Protein

Ben Margolis

Microtubule Motors in Establishment of Epithelial Cell Polarity Geri Kreitzer and Monn Monn Myat

Role of Polarity Proteins in the Generation and

Organization of Apical Surface Protrusions Gerard Apodaca

Polarized Exocytosis Jingwen Zeng, Shanshan Feng, Bin Wu, et al.

Regulation of Transporters and Channels by Membrane-Trafficking Complexes in Epithelial Cells

Curtis T. Okamoto

Membrane Transport across Polarized Epithelia Maria Daniela Garcia-Castillo, Daniel J.-F. Chinnapen and Wayne I. Lencer

Mechanisms of Cell Polarity-Controlled Epithelial Homeostasis and Immunity in the Intestine Leon J. Klunder, Klaas Nico Faber, Gerard Dijkstra, et al.

For additional articles in this collection, see http://cshperspectives.cshlp.org/cgi/collection/

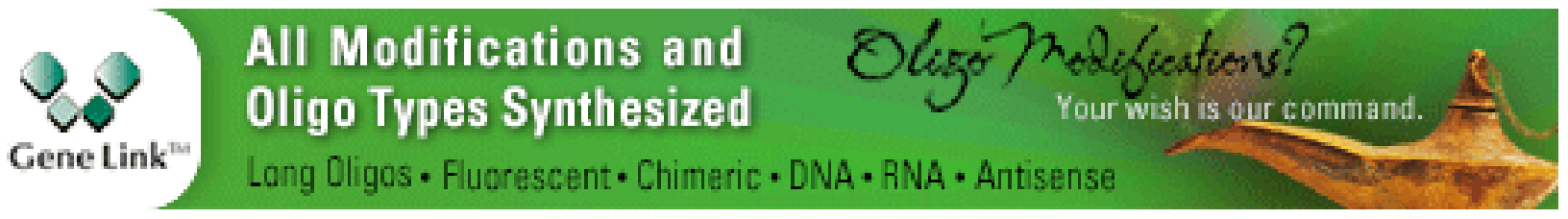


Targeting the Mucosal Barrier: How Pathogens Modulate the Cellular Polarity Network Travis R. Ruch and Joanne N. Engel
The Biology of Ciliary Dynamics

Kuo-Shun Hsu, Jen-Zen Chuang and Ching-Hwa Sung

For additional articles in this collection, see http://cshperspectives.cshlp.org/cgi/collection/

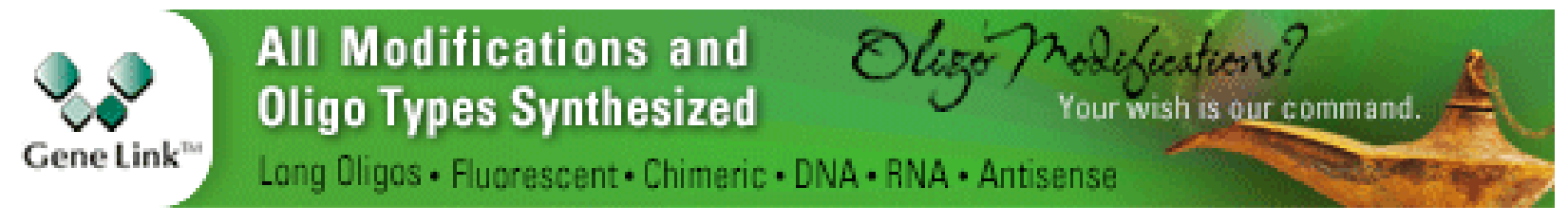

Copyright @ 2017 Cold Spring Harbor Laboratory Press; all rights reserved 